\section{Movement for Health: stopping the decline by building on bright spots and new evidence}

\author{
Steve Aspinall
}

Gloomy headlines are familiar; according to the WHO, an estimated 3.2 million deaths globally are caused by inactivity. On the other hand, we as health professionals know the solution-regular physical activity of a moderate intensity can also reduce the risk of type 2 diabetes, cardiovascular diseases, breast and colon cancer as well as improving bone and joint health. But the big challenges is how to implement our knowledge and grow our influence.

There is evidence of many very positive steps in the right direction. The fantastic Daily Mile programme gets our children moving whatever the weather and the excellent Movement for Movement global resources are now being used in medical and allied health educational programmes (see page 767 ). Only this morning, the UK's most popular radio show had the popular activity proponent Professor Greg Whyte discussing activity strategies for the desk-bound office worker.

The BJSM community has contributed a great deal to knowledge in this area, including an expert statement looking at the sedentary office. ${ }^{1}$ BJSM has published special issues on physical activity and health and is committed through Senior Associate Editor Emmanuel Stamatakis to keep this focus front of mind. This current issue contributes even more to this knowledge base. Read on!

\section{WHAT'S NEW IN THIS BASRAT ISSUE?}

The distinction between physical activity and sedentary behaviour is an important one, and there is debate whether you can outrun the harmful effects of sedentary behaviour. The systematic review by Ryan Falck (see page 800) and colleagues from Canada Research Chair Teresa Liu-Ambrose's research group contributes to this discussion by concluding that sitting behaviour is associated with inferior cognitive performance.

Do you prescribe therapeutic exercise to older adults with hip/knee osteoarthritis and/or low back pain? If yes, then the cutting-edge systematic review and meta-analysis by native Kiwi Philippa Nicolson and Australian colleagues (see page 791) goes some way to addressing

School of Health Sciences, University of Salford, Salford, Manchester, UK

Correspondence to Stephen Aspinall

S.J.Aspinall@salford.ac.uk the challenge of how to maximise exercise adherence. We all know what our patients need to do but getting them to do it over the long term is the biggest challenge.

Continuing to focus on pain and osteoarthritis, this time in the patellofemoral joint, the systematic review by postdoc Dr Harvi Hart from Professor Kay Crossley's group at $\mathrm{La}$ Trobe University in Australia offers further insight into the relationship between these conditions and BMI. The rigorous review (see page 781) provides a direction for future research and treatment decisions. In a literature review about a different, very active population, Antwerp University's shoulder physiotherapist, Dr Filip Struyf and colleagues give us an in-depth look at the evidence base around the swimmers' shoulders, including mechanisms, impairments and how rehabilitation strategies could be developed (see page 775).

Nutrition guidance has been getting ever more confusing for the public, with numerous and frequently conflicting messages coming from different professionals, many with valid objections to the existing guidelines. In her narrative review of four systematic reviews, Dr Zoe Harcombe from Wales, looks critically at the evidence base for the current guidelines and gives guidance for their update (see page 769 ).

Are all sports and types of exercise equal? In a large population-based cohort study of UK participants (see page 812), an international team found interesting independent associations among six different sports/types of exercise with all-cause and CVD mortality. Was your sport among the winners? This paper also has an infographic (see page 824). BJSM benefits from $\mathrm{Dr}$ Yann Le Meur's infographics (https://ylmsportscience.com/) and the leadership of Dr Andrew Murray (@DocAndrewMurray) in knowledge translation.

\section{BASRAT 2017 NATIONAL SYMPOSIUM-17 NOVEMBER MANCHESTER}

Join us at the Etihad Stadium in Manchester on Friday 17 November for our 2017 BASRaT National Symposium. Our worldclass line-up this year includes stellar keynote speakers, excellent practical workshops and stimulating speakers from a variety of sport disciplines and clinical backgrounds.
Our keynote guests are Vancouver's Professor Karim Khan, Editor in Chief of BJSM and Dr Tasha Stanton, a specialist in pain and neuroscience research with the renowned Body in Mind Research Group located in Adelaide, Australia, which is led by Professor Lorimer Moseley.

Our national symposium is renowned for the range and quality of practical workshops. The inspirational Dr Juliet McGrattan, GP and physical activity champion, will share her knowledge on exercise for health and well-being; Keith Cronin will provide you with two new clinical skill sets and Dr Paul Comfort will share cutting-edge strength and conditioning research to practical rehabilitation strategies. Designed to link theory and expert knowledge so they can be applied, we guarantee that you will gain expertise that can be applied to practice immediately.

The conference is aimed at all healthcare practitioners including sports rehabilitators, physiotherapists, sports therapists, osteopaths, chiropractors and doctors. Book now at www.basrat.eventbrite.co.uk

You will find updates on the BASRaT website, on our Twitter page @BASRaTSymposium and our Sport Rehab Facebook page.

\section{ABOUT BASRAT}

BASRaT is the UK regulator for sports rehabilitators and an advocate of the multidisciplinary healthcare team. BASRaT guides sports rehabilitators on all aspects of their role and responsibilities, ensuring public protection, professional competency and continued professional development.

The BASRaT register of sports rehabilitators has been approved as an accredited register by the Professional Standards Authority for Health and Social Care. For more detail please visit us at www.basrat.org.

\section{Competing interests None declared.}

Provenance and peer review Commissioned; internally peer reviewed.

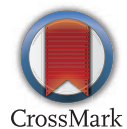

To cite Aspinall S. Br J Sports Med 2017;;51:759.

Br J Sports Med 2017:51:759.

doi:10.1136/bjsports-2017-097896

(C) Article author(s) (or their employer(s) unless otherwise stated in the text of the article) 2017. All rights reserved. No commercial use is permitted unless otherwise expressly granted.

\section{REFERENCE}

1 Buckley JP, Hedge A, Yates T, et al. The sedentary office: an expert statement on the growing case for change towards better health and productivity. $\mathrm{Br} J$ Sports Med 2015;49:1357-62 